\title{
Verbesserte Methode zur Bestimmung der Serumarginaseaktivität
}

\author{
Von R. Dargel
}

Aus dem Physiologisch-chemischen Institut der Universität Leipzig (komm. Direktor: Doz. Dr. Rotzsch)

(Eingegangen am 27. Juli 1965)

\begin{abstract}
Nach einer kurzen Übersicht über das Vorkommen der Arginase und der klinischen Bedeutung der Änderungen ihrer Aktivität im Blut wird ein Verfahren zur Bestimmung der Serum-Arginase-Aktivität angegeben. Gegenüber zahlreichen bisher durchgeführten Verfahren zu ihrer Bestimmung erwies sich die hier erstmalig angewandte Kombination der enzymatischen Zersetzung des während der Inkubation entstandenen Harnstoffes mit der Ammoniakbestimmungsmethode nach E. J. ConwaY als spezifischer und für Routinebestimmungen in der Klinik als handlicher bei gleich großer Genauigkeit.
\end{abstract}

The occurrence of arginase and the clinical significance of changes in its level in the blood are briefly reviewed. A method for the determination of serum arginase activity is then given. The present method is the first to combine the enzymic decomposition of the urea, which is formed during the incubation, with the method of E. J. ConwaY for the determination of ammonia. Compared with the numerous other methods, which have been so far tried, it is more specific, more convenient for routine clinical determinations and equally accurate.

Die von Kossel und Dakin 1904 entdeckte Arginase (L-Argininureohydrolase 3. 5. 3. 1) ist im Tier- (1) und Pflanzenreich (2) weit verbreitet. Insbesondere die Untersuchungen von S. EDLBACHER und RöTHLER (1) lassen erkennen, daß das Enzym nicht nur in der Leber der Mammalia als dem Ort der Harnstoffsynthese lokalisiert, sondern auch in Niere, Hoden und Plazenta zu finden ist. Darüber hinaus zeigen Leber und Niere von Hühnern (3) einen relativ hohen Arginasegehalt. Spätere Untersuchungen von Kochakian und Mitarbeitern (4) erbrachten im Gegensatz zu den Befunden von EDLbACHER und RötHLER (1) auch im Serum und Erythrozyten der Mammalia das Vorhandensein der Arginase.

Die bisher zur Bestimmung der Arginaseaktivität angewandten Verfahren schienen uns zu aufwendig oder zeitraubend, um für klinische Routine-Untersuchungen in Frage zu kommen. Aus zahlreichen Untersuchungen geht aber hervor, daß sowohl bei Erkrankungen der Leber als auch des erythropoetischen Systems Veränderungen der "SAR (1) zu beobachten und somit häufige Kontrollen angebracht sind. ManNING und Grisolia (5) sowie VINCENT und Huc (6) fanden bei entzündlichen Lebererkrankungen Erhöhungen der SARAktivität, die besonders kräftig bei akuter Hepatitis epidemica auftreten sollen (7), wobei jedoch die Veränderungen der SAR und SGOT nicht parallel gehen. PeLIKÁN und Mitarbeiter (8) verglichen die bei Hepatitis epidemica beobachteten Änderungen der Arginaseaktivität im Plasma mit der in den Erythrozyten. Während die Plasmaarginaseaktivität die entzündlichen Veränderungen widerspiegelt, läßt die Untersuchung der Erythrozytenarginase keine diagnostischen Schlüsse auf akute Lebererkrankungen zu. Von REYNOLDs und Mitarbeitern (9) werden auffällige Erhöhungen dèr Arginaseaktivität in den Erythrozyten bei perniciöser Anämie sowie bei

1) Abkiirzıngen: SAR: Serumarginase; L-Argininureohydrolase 3. 5. 3.1

SGOT: Serum-L-Aspartat: 2-Oxoglutarat-Aminotransferase (2.6.1.1) makrozytären Anämien beschriebeñ. Für wiederholte Untersuchungen der SAR ist jedoch ein handliches Verfahren notwendig. Ein solches haben wir für unsere Untersuchungen der Leberarginase von Ratten ausgearbeitet ${ }^{2}$ ). Über die Bestimmung der SAR mit dieser Methode soll im folgenden berichtet werden.

\section{Methodik}

Zur Bestimmung der SAR pipettierten wir zu $0,4 \mathrm{~m} /$ eines $0,1 \mathrm{~m}$ Glycinpuffers $\mathrm{pH} 9,0$ und $0,1 \mathrm{~m} l$ einer Mangansulfat- $\left(4.10^{-2} \mathrm{~m}\right)$ Malatlösung $\left(1.10^{-2} \mathrm{~m}\right) 0,2 \mathrm{~m} /$ Serum und präinkubierten $30 \mathrm{Min}$. bei $38^{\circ}$. Dann fügten wir $0,1 \mathrm{~m} /$ einer $0,15 \mathrm{~m} \mathrm{~L}-(+)$-Argininlösung $(\mathrm{pH} 9,0)$ hinzu und inkubierten $24 \mathrm{Stdn}$. bei $38^{\circ}$. Anschließend wurde die Arginase durch Zugabe von $0,04 \mathrm{~m} / 2 n \mathrm{HCl}$ und Inkubation über $30 \mathrm{Min}$. bei gleicher Temperatur inaktiviert. Danach gaben wir $0,35 \mathrm{ml} 0,5 \mathrm{~m}$ Phosphatpuffer $\mathrm{pH} \mathrm{7,3} \mathrm{hinzu,} \mathrm{der} 4 \mathrm{mg}$ Urease $/ \mathrm{m} l$ enthielt und inkubierten nochmals $30 \mathrm{Min}$. bei $38^{\circ}$. In einem aliquoten Teil der Inkubationsflüssigkeit wurde mittels der Mikrodiffusionsmethode nach Conway und MaLLEY (10) der Ammoniak bestimmt. Dieser wurde mit Kaliumkarbonat verdrằngt und im zentralen Gefäßteil in $2 \mathrm{~m} / 0,5$-proz. alkoholischer Borsäure aufgefangen. Als Verschlußmittel der Conway-Schälchen verwandten wir mit gutem Erfolg reines Paraffin (Fp. 55\%). Die Titration erfolgte mit 0,005 n Schwefelsäure.

Um den präformierten Harnstoff im Serum zu bestimmen, liefen jeweils zwei Serumkontrollen parallel, indem vor Argininzusatz durch Zugabe von $\mathrm{HCl}$ die Arginase inaktiviert worden war. Die Differenz der Haupt- zu den Kontrollwerten ergibt die Menge des auf Grund der Arginasewirkung gebildeten Harnstoffs, die - auf 24 Stunden und $100 \mathrm{~m} l$ Serum bezogen ein $\mathrm{Maß}$ für die Arginaseaktivität darstellt.

Bei 10 Versuchspersonen betrug die SAR-Aktivität $44,5 \pm 22,3 \mathrm{mg}$ Harnstoff/24 Stdn. und $100 \mathrm{ml}$ Serum. Die Standardabweichung für 10 Dreifachbestimmungen belief sich auf $1,7 \mathrm{mg}$ Harnstoff pro $100 \mathrm{~m} l$ Serum. Die Versuchspersonen stammten aus dem Patientengut einer chirurgischen Klinik. Sie zeigten keinerlei klinisch nachweisbare Stoffwechselstörungen.

2) Teilweise vorgetragen auf dem 4. Jahreskongreß der Arbeitsgemeinschaft Klinische Pathologie und Klinische Chemie in der Gesellschaft für experimentelle Medizin, Erfurt 1965. 


\section{Diskussion}

Die Arginaseaktivität kann einerseits durch die $\mathrm{Be}-$ stimmung des pro Zeiteinheit zersetzten Arginins (11), andererseits mittels des während der Inkubation entstandenen Harnstoffs erfolgen $(1,3,7,8)$. Bei Anwendung des letzteren Prinzips erweisen sich die Ureasemethoden gegenüber zahlreichen anderen Harnstoffbestimmungsmethoden als weitaus spezifischer, da lediglich Harnstoff erfaßt wird und andere im Serum vorhandene Stoffe keine Störungen verursachen. Bei der Harnstoffbestimmung mit p-Dimethylaminobenzaldehyd dagegen stört Arginin, das ebenso wie Harnstoff ein Kondensationsprodukt mit dem Aldehyd gibt, dessen Absorptionsbanden gleichfalls bei $415 \mathrm{~m} \mu$ und $440 \mathrm{~m} \mu$ liegen (12). Die Reaktion nach Fearon mit Diacetylmonoxim und Isonitrosopropiophenon folgt nicht dem LambertBeerschen Gesetzt (5), ist photosensibel (13) und wird durch Medikamente gestört (14). Eine umfangreiche Darstellung über den Einfluß zahlreicher, gleichfalls mit Isonitrosopropiophenon reagierender Substanzen gibt Archibald (15).

Die mit der enzymatischen Harnstoffzersetzung kombinierten Ammoniakbestimmungsmethoden waren $z u$ aufwendig, wie etwa das manometrische (16), das konduktometrische (17) oder das elektrometrische (18) Verfahren. Die enzymatischè Bestimmung des Ammo- niaks mittels Glutaminsäuredehydrogenase (19) ist für Routineuntersuchungen zu zeitraubend; für die neßlerometrische $\mathrm{NH}_{3}$-Bestimmung gibt MASSMANN (20) zahlreiche Fehlermöglichkeiten an. Wir haben aus diesem Grunde das Mikrodiffusionsverfahren gewählt, für das E. J. Conway eine Empfindlichkeit von $0,15 \mathrm{mg}$ Harnstoff/100 ml Blut angab. Neben dem geringen apparativen Aufwand dieses Verfahrens ist von Vorteil, daß lecliglich die $\mathrm{NH}_{3}$-haltige Flüssigkeit exakt einpipettiert werden muß, während geringe Schwankungen der Borsäure- und Kaliumkarbonatmengen keine Fehler verursachen. Die Genauigkeit des angewandten Verfahrens liegt im Bereich anderer Ammoniakbestimmungen $(16,20,21)$.

Damit erweist sich die von uns durchgeführte Methode gegenüber zahlreichen anderen Methoden zur Bestimmung der Arginaseaktivität (11, 12, 22, 23) als spezifischer, weniger störanfällig und weitaus handlicher, was ihre Anwendung als Routinemethode wesentlich begünstigt. Ein Vergleich der von uns gefundenen SARWerte mit denen anderer Autoren ist nicht möglich, da letztere z. T. ohne Mn-Aktivierung oder unter anderen Inkubationsbedingungen gearbeitet haben. Es wäre nützlich, auch hier Standardbedingungen einzuführen, damit Vergleiche der Arginaseaktivitäten möglich werden.

\section{Literatur}

1. Edrbacher, S. und H. Röthler, Hoppe-Seylet's Z. physiol. Chem. 148, 273 (1925). - 2. KresE, A., Hoppe-Seyler's Z. physiol. Chem. 60, 460 (1903). - 3. Tamir, H. und S. RatNer, Arch. Biochem. Biophysics 102, 249 (1963). - 4. Kochakian, Ch. D., G. KentmanN und G. Garber, in E. C. ReifensteIN, Conference on Metabolic Aspects of Convalescence, S. 187, New York (1948). - 5. Manning, R. T. und S. Grisolia, Proc. Soc. exp. Biol. Med. 95, 225 (1957). - 6. VINCENT, D. und J. Huc, C. R. SÉances Soc. Biol. Filiales 136, 819 (1942). - 7. Ugarte, C., E. Pino, P. Peirano und E. Marusic, J. Laborat. Clin. Med., S. Louis 55, 522 (1960). - 8. Pelikán, C., M. Kalab und J. Trchy, Clin. Chim. Acta (Amsterdam) 9, 141 (1964). - 9. ReYnolds, J., J. H. FolletTe und W. N. VALENTINE, J. Laborat. Clin. Med., S. Louis 50, 78 (1947). - 10. Conway, E. J. und E. O'Malley, Biochem. J. 36, 655 (1942). - 11.
Morgue, M. und R. Baret, C. R. Seances Soc. Biol. Filiales 150, 550 (1956). - 12. KALÁB, M. und V. PeLIKÁN, Collect. czechoslov. chem. Commun. 27, 1639 (1962). - 13. Coulombe, J. J. und L. Favreau, Clin. Chem. (New York) 9, 102 (1963). - 14. Mrchon, J. und R. Arnaud, Clin. Chim. Acta (Amsterdam) 7, 739 (1962). 15. Archibald, R. M., J. biol. Chemistry 157, 507 (1945). - 16. Krebs, H. A. und K. Henseleit, Hoppe-Scyler's $Z$. physiol. Chem. 210, 33 (1932). - 17. Chin, W. T. und W. Kroontje, Analytic. Chem. 33, 1757 (1961). - 18. Nielsen, I., Scand. J. Clin. Laborat. Invest. 14, 513 (1962). - 19. Kirsten, E., C. Gerez und R. Kirsten, Biochem. Z. 337, 312 (1963). - 20. Massmann, W., Z. analyt. Chem. 193, 332 (1963). - 21. Searcy, R. L. und F. M. Cox, Clin. Chim. Acta (Amsterdam) 8, 810 (1963). - 22. Jansen, K., Chem. Weekbl. 14, 125 (1917). 23. Weir, L. und M. A. Russell, J. biol. Chemistry 106, 505 (1934).
Dr. R. Dargel

Physiologisch-chemisches Institut der Universität

Leipzig C 1, Liebigstr. 16 